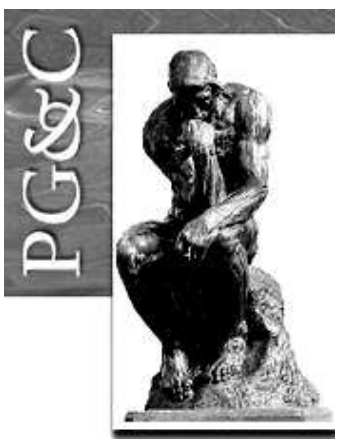

\title{
O PAPEL DA CULTURA ORGANIZACIONAL NA GESTÃO DO CONHECIMENTO: REVISÃO DE LITERATURA DE 2009 A 2015
}

\author{
Antonio de Paula Braquehais \\ Mestrando em Gestão do Conhecimento e Tecnologia da Informação pela \\ Universidade Católica de Brasília, Brasil. \\ E-mail: braquehais@gmail.com \\ Julieta Kaoru Watanabe Wilbert \\ Doutoranda em Engenharia e Gestão do Conhecimento pela \\ Universidade Federal de Santa Catarina, Brasil. \\ E-mail: julieta.wilbert@gmail.com \\ Eduardo Amadeu Dutra Moresi \\ Doutor em Ciência da Informação pela Universidade de Brasília, Brasil. \\ Professor da Universidade Católica de Brasília, Brasil. \\ E-mail: moresi@ucb.br

\section{Gertrudes Aparecida Dandolini} \\ Doutora em Engenharia de Produção pela Universidade Federal de Santa \\ Catarina, Brasil. Professora da Universidade Federal de Santa Catarina, Brasil. \\ E-mail: gtude@egc.ufsc.br
}

\begin{abstract}
Resumo
A Cultura Organizacional emerge como fator promotor ou inibidor para implementação e manutenção da Gestão do Conhecimento. Embora o vínculo entre os dois construtos seja mencionado na literatura, ainda são escassas pesquisas publicadas que investigam essa relação. Para cobrir tal lacuna, este estudo realizou uma revisão sistemática no Portal Capes sobre o papel da Cultura Organizacional na Gestão do Conhecimento no Brasil e no mundo, nos últimos cinco anos. Abordaram-se os principais modelos teóricos e métodos que servem de base para os estudos mais recentes nos temas da Cultura Organizacional e da Gestão do Conhecimento, apresentando-se os principais resultados. Estes sugerem que, além da necessidade de se atentar para os efeitos positivos e negativos de uma Cultura Organizacional sobre práticas de Gestão do Conhecimento, é importante realizar a identificação da cultura ou subcultura prevalente em uma organização ou grupo. Conclui-se, assim, que os estudos selecionados alertam para a necessidade de ações para a criação de uma cultura favorável para a implementação de práticas de Gestão do Conhecimento, de forma a aumentar as chances de seu sucesso em organizações. A limitação principal da pesquisa é a amostra limitada de artigos selecionados. O artigo contribui para que estudiosos da área de Cultura Organizacional e de Gestão do Conhecimento obtenham visão geral dos estudos publicados nos últimos cinco anos como base para pesquisas futuras.
\end{abstract}

Palavras-chaves: Cultura Organizacional. Gestão do Conhecimento. Revisão de Literatura. 


\title{
THE ROLE OF ORGANIZATIONAL CULTURE IN KNOWLEDGE MANAGEMENT: A LITERATURE REVIEW FROM 2009 TO 2015
}

\begin{abstract}
Organizational Culture emerges as a promoting or an inhibiting factor for implementing and maintaining Knowledge Management. Although the relationship between the two constructs has been mentioned in the literature, there still have been very few research publications about this subject in the last five years. In order to cover this gap, the present study conducted a literature review on the role of Organizational Culture in Knowledge Management in Brazil and in the world. Articles published in the last five years from the Portal Capes, a Brazilian scientific database, were considered in the current review. The study addresses the main theoretical models and methods that form the basis of the most recent studies on issues of Organizational Culture and Knowledge Management. In summary, the studies suggest that in addition to the need to pay attention to the positive and negative effects that Organizational Culture may have on Knowledge Management practices, it is important to carry out the identification of the prevalent culture or subculture in an organization or group. The studies of the past five years on the subject under discussion highlight the need for implementing ways to promote a favorable culture for applying Knowledge Management practices successfully. The main limitation of this study is the small sample of selected articles. The article helps students of Organizational Culture and Knowledge Management to get an overview of the studies published during the last five years.
\end{abstract}

Keywords: Organizational Culture. Knowledge Management. Literature Review.

\section{INTRODUÇÃO}

A Gestão do Conhecimento (GC) vem sendo alvo de estudos mais intensos na academia desde o início dos anos 2000, com a conscientização de que o conhecimento é um recurso vital para a economia do século 21 (MEYER; SUGIYAMA, 2007). Nos contextos da GC, a Cultura Organizacional (CO) emerge como fator promotor ou inibidor para sua implementação e manutenção.

A Gestão do Conhecimento (GC) entendida como a disciplina para facilitar a criação, armazenamento, transferência e aplicação do conhecimento organizacional, tem recebido grande atenção nas práticas e pesquisas nos últimos tempos (ALAVI; KAYWORTH; LEIDNER, 2005), tendo chegado em um estágio do seu ciclo de vida em que se busca o melhor entendimento dos fatores críticos de sucesso (HEISIG, 2009).

A Cultura Organizacional (CO) pode ser compreendida como um conjunto de normas sociais que definem regras ou contexto para interações sociais por meio das quais as pessoas agem e se comunicam (SCHEIN, 2009), sendo frequentemente citada como um desafio significante nas práticas de GC (ALAVI; KAYWORTH; LEIDNER, 2005; HEISIG, 2009).

Uma revisão da literatura dos estudos e pesquisas nos temas da Cultura Organizacional e da Gestão do Conhecimento nos últimos cinco anos, apresenta várias indicações de que são conceitos associados (AL-ALAWI; AL-MARZOOQI; MOHAMMED, 2007; ALAVI; KAYWORTH; LEIDNER, 2005; CHANG; LIN, 2015; DONATE; GUADAMILLAS, 2010; NGUYEN; MOHAMED, 2011; SOUZA; ZIVIANI; GOULART, 2014; WANG; SU; YANG, 2011; WIEWIORA et al., 2013).

No entanto, apesar de inúmeros estudos sobre a influência da $\mathrm{CO}$ e de valores culturais nas práticas e processos da GC, não foi identificada uma revisão da literatura sobre a relação destes dois temas nos últimos cinco anos.

O objetivo do presente artigo é descrever as principais definições, transformações que ocorreram com essa temática no período investigado e analisar os modelos teóricos, métodos e resultados da pesquisa utilizados para investigar a temática. Com base nessa análise, diagnosticar lacunas de investigação relativas a método e teoria; e, levantar questões de pesquisa relevantes sobre o tema.

A estratégia de investigação empregada é a revisão da literatura dos estudos e pesquisas nos temas da Cultura Organizacional e da Gestão do Conhecimento nos últimos cinco anos. Ao

Perspectivas em Gestão \& Conhecimento, João Pessoa, v. 7, Número Especial, p. 80-93, mar. 2017. 
levantamento e à análise dos artigos acadêmicos sobre a influência da CO na GC no Brasil e no mundo, provenientes do portal da CAPES, foram adicionadas pesquisas em livros por meio de busca dirigida ao tema. Com isso obteve-se uma visão panorâmica dos principais modelos teóricos e métodos que servem de base para os estudos mais recentes nos temas da CO e GC, com apresentação dos principais resultados. Por fim o presente estudo apresenta uma análise das principais limitações das investigações dos pontos de vista metodológico e teórico na visão dos autores, bem como um conjunto de questões de pesquisa relevantes sobre o tema propostas por eles.

\section{GESTÃO DO CONHECIMENTO E CULTURA ORGANIZACIONAL}

Para Davenport, De Long e Beers (1998) conhecimento é a informação combinada com experiência, contexto, interpretação e reflexão, que pode ser usado para a tomada de decisão e para a ação.

Segundo Nonaka e Takeuchi (1995), para gerar valor para as empresas, responder rapidamente aos seus clientes, criar novos mercados, desenvolver agilmente novos produtos e dominar tecnologias emergentes, as empresas devem adotar uma abordagem exclusiva da gestão da criação de novos conhecimentos por meio da GC.

A essência da abordagem proposta é o reconhecimento de que a criação do conhecimento não se refere apenas ao processamento de informações objetivas, e sim da exploração dos insights tácitos e subjetivos das organizações e de seus indivíduos tornando-os disponíveis para testes e para uso em toda a organização (NONAKA; TAKEUCHI, 1995).

Gestão do Conhecimento (GC) é definida como o processo de criação contínua de novos conhecimentos, de disseminação ampla dos mesmos na organização, incorporando-os rapidamente em novos produtos, serviços, tecnologias e sistemas, que perpetuam a mudança no interior da organização (TAKEUCHI; NONAKA, 2008).

Para Alavi e Leidner (2001, p. 123) a GC deve ser entendido como:

Um conjunto de práticas e processos contínuos e dinâmicos envolvendo indivíduos, grupos e estruturas físicas, onde, em dado momento e em dada organização, indivíduos e grupos podem estar envolvidos em diferentes aspectos dos processos de gestão do conhecimento.

A Gestão do Conhecimento pode ocorrer por meio de quatro atividades chaves relativas ao conhecimento: criar, armazenar, compartilhar e utilizar (HEISIG, 2009). Ainda segundo Heisig (2009) o sucesso da gestão do conhecimento sustentável é influenciado pelo contexto e pelos fatores de cultura, organização e papéis, estratégia e liderança, habilidades e motivação, controle e monitoramento e tecnologia da informação.

A cultura é mencionada recorrentemente como um dos fatores que impactam a implementação da GC em organizações. Por exemplo, uma cultura impregnada pela burocracia e rigidez hierárquica impactam na implementações de práticas de GC como as comunidades de prática virtuais (STEFANCK; LESAGE, 2005), já que estas requerem um ambiente onde sejam possíveis interações espontâneas, informais e voluntárias (PAN; LEIDNER, 2003; NEUFELD; FANG; WANG, 2013). Nesse sentido, compreender a cultura organizacional torna-se relevante para a GC.

Conceituar cultura organizacional não decorre de posições consensadas, já que ela é estudada a partir de várias perspectivas (SOUZA-SILVA, 2009). A partir do início da década de 80, duas vertentes foram explicitadas: a mecanicista e a holográfica (RICHTER, 2002). Enquanto a abordagem mecanicista entende a CO como um composto de uma série de elementos (crenças, valores, normas, rituais e outros), o olhar holográfico entende a CO como o reflexo de como os

Perspectivas em Gestão \& Conhecimento, João Pessoa, v. 7, Número Especial, p. 80-93, mar. 2017. 
integrantes da organização a interpretam (idem). Essa última abordagem é a adotada por Schein (2009), e também assumida no presente artigo.

Assim, recordando a Schein (2009), a CO é entendida como uma interação contínua e dinâmica entre suposições básicas, valores e artefatos.

As suposições básicas ou crenças representam esquemas interpretativos que os indivíduos usam para perceber situações e interpretar acontecimentos em curso, atividades e relações humanas, formando assim as bases para ação coletiva (SCHEIN, 2009).

Valores representam uma manifestação mais visível da cultura que denotam crenças explicitadas, identificando o que é importante para um grupo cultural particular. Os valores podem ser vistos com o um conjunto de normas sociais que definem regras ou contexto para interações sociais por meio das quais as pessoas agem e se comunicam (SCHEIN, 2009).

Ainda segundo Schein (2009), artefatos são as manifestações mais visíveis da cultura organizacional. Incluem coisas tais como arte, tecnologia e padrões de comportamentos visíveis e audíveis, bem como mitos, heróis, linguagem, rituais e cerimônias.

A maioria dos estudos sobre a influência da CO na GC consideraram cultura organizacional em termos de seus valores, por diversas razões: primeiramente porque os valores, muitas vezes explicitados na identidade corporativa, são estudados mais facilmente do que as suposições básicas, que são invisíveis, e do que os artefatos, que são difíceis de interpretar. Em segundo lugar, porque trabalhos teóricos anteriores realizados com a temática da relação entre $\mathrm{CO}$ e comportamento grupais e suas ações se basearam em valores culturais (ALAVI; KAYWORTH; LEIDNER, 2005; CHANG; LIN, 2015).

A habilidade de transferir conhecimento entre indivíduos, grupos e organizações é considerando um importante fator de desenvolvimento da performance organizacional. Os benefícios do compartilhamento de conhecimento já foram bastante documentados, embora a efetividade entre diversas organizações seja bastante variável (ALAVI; KAYWORTH; LEIDNER, 2005; CHANG; LIN, 2015).

Valores culturais de colaboração e confiança são considerados importantes para melhorar o compartilhamento de conhecimento e a efetividade organizacional, com certo grau de evidência empírica para esta confirmação (SVEIBY; SIMONS, 2002).

Os estudos recentes sobre a influência da CO nas práticas de GC abordam a relação de alguns valores culturais com uma ou mais etapas do processo da GC. Alguns estudos analisam a influência de fatores da CO no compartilhamento de conhecimento (AL-ALAWI; AL-MARZOOQI; MOHAMMED, 2007; WIEWIORA et al., 2013), outros na criação de conhecimento (WANG; SU; YANG, 2011). Outros estudos ainda avaliam o papel dos fatores da CO na GC como um todo (ALAVI; KAYWORTH; LEIDNER, 2005; RAI, 2011; SOUZA; ZIVIANI; GOULART, 2014; CHANG; LIN, 2015).

Há estudos que combinam a análise de fatores culturais combinados com outros fatores tais como liderança estrutura e estratégia e sua influência das práticas de GC (NGUYEN; MOHAMED, 2011; ZHENG; YANG; MCLEAN, 2010).

Finalmente, existem estudos que avaliam o impacto da CO na GC e na inovação ou no desempenho da organização (DONATE; GUADAMILLAS, 2010; ZHENG; YANG; MCLEAN, 2010).

\section{PROCEDIMENTOS METODOLÓGICOS}

No presente trabalho de revisão da literatura foram utilizados os princípios de uma revisão sistemática conforme recomendado por Jesson, Matheson e Lacey (2011): a) Mapeamento do tema por meio dos termos "Cultura Organizacional" e "Gestão do Conhecimento"; b) Busca completa no portal da CAPES; c) Avaliação da qualidade segundo critério explicitado na sequência; d) Extração do conteúdo para análise; e) Síntese; e f) Redação.

Na busca inicial pelos termos "Cultura Organizacional" e "Gestão do Conhecimento" no portal da CAPES nos últimos cinco anos, foram encontrados doze artigos, sendo seis revisados por 
pares. Por meio dos termos em inglês "Organizational Culture" e "Knowledge Management" foram encontrados 514 artigos, sendo 458 revisados por pares. Como primeira forma de qualificação dos artigos encontrados, utilizou-se somente os artigos revisados por pares, resultando em 464 artigos no total.

Os artigos foram classificados por relevância segundo o tema de pesquisa, conforme recomenda Creswell (2013), e a partir daí foi selecionada uma amostra de três artigos em português e 47 artigos em inglês, totalizando 50 artigos.

Para a qualificação destes artigos foi avaliado o número de citações (mínimo de 50 citações, exceto para artigos mais recentes ou em língua portuguesa) e a classificação do periódico ou revista na qual foi publicado o artigo (WebQualis A1 e B1, exceto para os artigos em língua portuguesa), chegando-se ao número de nove artigos, aos quais foram incluídos os trabalhos de Alavi; Kayworthy; Leidner (2005) e (Al-Alawi; Al-Marzooqi; Mohammed (2007). O primeiro deles foi selecionado por ser um artigo de citação recorrente nos artigos encontrados, servindo de base de comparação de como os estudos nos temas da CO e GC evoluíram nos últimos anos. O segundo artigo foi escolhido por ser um estudo com um grande número de citações no tema estudado, sendo inferior em citações apenas em relação primeiro.

\section{RESULTADOS E ANÁLISE}

O Quadro 1 apresenta a lista dos onze artigos analisados na presente revisão de literatura. Na sequência apresentam-se os resultados explicitados por métodos de pesquisa e unidade de análise; fontes de publicação; modelos teóricos utilizados.

\subsection{Um tema estudado em vários países}

Os artigos estudados referem-se a estudos de caso e pesquisas empíricas em várias regiões do mundo, realizadas em organizações públicas e privadas, de diversos setores da economia.

As pesquisas apresentam estudos feitos em países desenvolvidos, tais como Estados Unidos, Espanha, bem como em países denominados emergentes: Brasil e China. Diversas culturas organizacionais foram estudadas tanto a cultura ocidental como a oriental.

As pesquisas incluem estudos em empresas de grande porte dos setores industriais e de alta tecnologia, bem como Micro e Pequenas Empresas - MPE's de diversos setores.

Enfocam ainda os aspectos da CO em relação as práticas de GC em Empresas Públicas e Privadas.

O Quadro 2 resume as Unidades de Análise dos Estudos de Caso e Pesquisas Empíricas analisadas.

Os resultados sugerem que investigações sobre a temática $\mathrm{CO}$ e sua associação à GC encontram-se distribuídas tanto a nível geográfico, quanto à natureza das organizações (pública/ privada) e às suas dimensões (pequena, média ou grande).

\subsection{Um tema de interesse das ciências da computação e da administração}

Como pode ser observado no Quadro 1, a maioria dos artigos analisados foi publicada em revistas associadas aos campos das Ciências da Computação e da Administração.

Apesar de a CO ser um campo de estudo do Comportamento Organizacional, o nível meso e macro da subárea da Psicologia do Trabalho e das Organizações (GONDIM; BORGES-ANDRADE; BASTOS, 2010), não foram encontrados artigos ligados à Psicologia no universo dos artigos selecionados para este estudo. 
Quadro 1 - Revisão da Literatura - Cultura Organizacional e Gestão do Conhecimento - Portal CAPES - 2010 - 2015

\begin{tabular}{|c|c|c|c|c|c|}
\hline Referência & Ano & Título do artigo/livro & Periódico/Editora & Citações & Classificação \\
\hline (ALAVI; KAYWORTH; LEIDNER, 2005) & 2005 & $\begin{array}{l}\text { An Empirical Examination of the Influence of Organizational } \\
\text { Culture on Knowledge Management Practices. }\end{array}$ & $\begin{array}{l}\text { Journal of Management } \\
\text { Information Systems }\end{array}$ & 484 & A1 \\
\hline $\begin{array}{ll}\text { (AL-ALAWI; } & \text { AL-MARZOOQI; } \\
\text { MOHAMMED, 2007) } & \end{array}$ & 2007 & $\begin{array}{l}\text { Organizational culture and knowledge sharing: critical success } \\
\text { factors }\end{array}$ & $\begin{array}{l}\text { Journal of Knowledge } \\
\text { Management }\end{array}$ & 406 & A1 \\
\hline (ZHENG; YANG; MCLEAN, 2010) & 2010 & $\begin{array}{l}\text { Linking organizational culture, structure, strategy, and } \\
\text { organizational effectiveness: Mediating role of knowledge } \\
\text { management. }\end{array}$ & $\begin{array}{l}\text { Journal of Business } \\
\text { Research }\end{array}$ & 367 & A1 \\
\hline (DONATE; GUADAMILLAS, 2010) & 2010 & $\begin{array}{l}\text { The effect of organizational culture on knowledge } \\
\text { management practices and innovation. }\end{array}$ & $\begin{array}{l}\text { Knowledge and Process } \\
\text { Management }\end{array}$ & 56 & B1 \\
\hline (NGUYEN; MOHAMED, 2011) & 2011 & $\begin{array}{l}\text { Leadership behaviors, organizational culture and knowledge } \\
\text { management practices; An empirical investigation. }\end{array}$ & $\begin{array}{l}\text { Journal of Management } \\
\text { Development }\end{array}$ & 56 & - \\
\hline (WANG; SU; YANG, 2011) & 2011 & Organizational culture and knowledge creation capability. & $\begin{array}{l}\text { Journal of Knowledge } \\
\text { Management }\end{array}$ & 63 & A1 \\
\hline (RAI, 2011) & 2011 & $\begin{array}{l}\text { Knowledge management and organizational culture: a } \\
\text { theoretical integrative framework. }\end{array}$ & $\begin{array}{l}\text { Journal of Knowledge } \\
\text { Management }\end{array}$ & 51 & A1 \\
\hline (PRADO; BEM; DELFINO, 2013) & 2013 & $\begin{array}{l}\text { Desafios à implantação da gestão do conhecimento: a } \\
\text { questão cultural nas organizações públicas federais. }\end{array}$ & $\begin{array}{lr}\text { Revista Digital de } \\
\text { Biblioteconomia e } \\
\text { Ciência da Informação }\end{array}$ & 2 & B3 \\
\hline (WIEWIORA et al., 2013) & 2013 & $\begin{array}{l}\text { Organizational culture and willingness to share knowledge: A } \\
\text { competing values perspective in Australian context. }\end{array}$ & $\begin{array}{l}\text { International Journal of } \\
\text { Project Management }\end{array}$ & 30 & A1 \\
\hline (SOUZA; ZIVIANI; GOULART, 2014) & 2014 & $\begin{array}{l}\text { Interseção entre a Gestão do Conhecimento e a Cultura } \\
\text { Organizacional: Um Estudo sobre a Percepção dos Gerentes } \\
\text { de Projetos. }\end{array}$ & $\begin{array}{l}\text { Revista de Gestão e } \\
\text { Projetos }\end{array}$ & 1 & B3 \\
\hline (CHANG; LIN, 2015) & 2015 & $\begin{array}{l}\text { The role of organizational culture in the knowledge } \\
\text { management process. }\end{array}$ & $\begin{array}{l}\text { Journal of Knowledge } \\
\text { Management }\end{array}$ & 1 & A1 \\
\hline
\end{tabular}

Fonte: Portal CAPES (2015) 
Quadro 2 - Unidade de Análise dos Estudos e Pesquisas Analisados

\begin{tabular}{|l|l|}
\hline \multicolumn{1}{|c|}{ Referência } & \multicolumn{1}{|c|}{ Unidade de análise } \\
\hline $\begin{array}{l}\text { (ALAVI; KAYWORTH; LEIDNER, 2005) } \\
\text { (AL-ALAWI; AL-ARZOOQI; MOHAMMED, }\end{array}$ & Organde companhia de tecnologia nos EUA \\
\hline (ZHENG; YANG; MCLEAN, 2010) & Organizações do centro-oeste Americano - EUA \\
\hline (DONATE; GUADAMILLAS, 2010) & Grandes empresas do setor industrial - Espanha \\
\hline (NGUYEN; MOHAMED, 2011) & Micro e Pequenas Empresas - Austrália \\
\hline (WANG; SU; YANG, 2011) & Empresas de diversos setores - China \\
\hline (RAI, 2011) & Índia \\
\hline (PRADO; BEM; DELFINO, 2013) & Órgãos da Administração Pública Brasileira \\
\hline (WIEWIORA et al., 2013) & Empresa de Gestão de Projetos (BPO) - Austrália \\
\hline (SOUZA; ZIVIANI; GOULART, 2014) & Gestores de Projetos PMI - Minas Gerais \\
\hline (CHANG; LIN, 2015) & $\begin{array}{l}\text { Empresas públicas e privadas de diversos } \\
\text { setores - Taiwan }\end{array}$ \\
\hline
\end{tabular}

Fonte: Autoria própria (2015)

O que se pode depreender do Quadro 1 é que pesquisadores das áreas das ciências computacionais e de administração têm se destacado pela qualidade de seus trabalhos, considerando a classificação de suas publicações em ranking de periódicos e/ou número de citações.

\subsection{Principais definições, transformações que ocorreram com essa temática no período investigado}

No campo da Gestão do Conhecimento, a maioria dos estudos se utilizam das definições de conhecimento e de GC de Davenport et al. (1998), de Nonaka e Takeuchi (2008), e de Batista (2012).

Nesse contexto, conhecimento é a informação combinada com experiência, contexto, interpretação e reflexão, que pode ser usado para a tomada de decisão e para a ação (DAVENPORT; DE LONG; BEERS, 1998).

GC é o processo de criação contínua de novos conhecimentos, de disseminação ampla dos mesmos na organização, incorporando-os rapidamente em novos produtos, serviços, tecnologias e sistemas, que perpetuam a mudança no interior da organização (NONAKA; TAKEUCHI, 2008).

Na administração pública, a GC deve estar atrelada aos princípios básicos do serviço público: eficiência, qualidade, efetividade social, e aos princípios constitucionais da legalidade, impessoalidade, moralidade, publicidade e eficiência (BATISTA, 2012).

Os conceitos analisados nos estudos encontrados evoluíram com os conceitos dos próprios autores citados anteriormente.

Por exemplo, Alawi, Kayworth e Leidner (2005) conceituam GC como um conjunto de práticas e processos contínuos e dinâmicos envolvendo indivíduos, grupos e estruturas físicas,

Perspectivas em Gestão \& Conhecimento, João Pessoa, v. 7, Número Especial, p. 80-93, mar. 2017. 
onde, em dado momento e em dada organização, indivíduos e grupos podem estar envolvidos em diferentes aspectos dos processos de gestão do conhecimento. Zheng, Yang e McLean (2010) afirmam com base em Demarest (1997), Rowley (2001) e Soliman e Spooner (2000) que a GC engloba o esforço gerencial em facilitar as atividades de aquisição, criação, armazenamento, compartilhamento, difusão e implementação de conhecimento pelos indivíduos e grupos. Para Wang, Su e Yang (2011), a GC é a habilidade de uma organização de compartilhar e combinar conhecimento para a criação de novos conhecimentos. Souza, Ziviani e Goulart (2014) definem a GC como o processo de criação contínua de novos conhecimentos, de disseminação ampla dos mesmos na organização, incorporando-os rapidamente em novos produtos, serviços, tecnologias e sistemas. A GC, para eles, perpetua a mudança no interior da organização. Com base em Davenport e Prussak (2000) e Leidner e Kayworth (2006), Chang e Lin (2015) definem que a GC é o processo de captura, armazenamento, compartilhamento, e uso de conhecimento.

No campo da CO, os conceitos mais referenciados são aqueles de Schein (2009) e Hofstede et al. (1990). Resgatando ao primeiro, CO é entendida como uma interação contínua e dinâmica entre suposições básicas, valores e artefatos. Hofstede et al. (1990) amplia essa visão, afirmando que a cultura organizacional pode ser vista como um universo cultural constituído de pressupostos, valores e crenças partilhados pelos indivíduos da organização, tendo derivação do ambiente social (HOFSTEDE et al., 1990).

Os autores dos artigos selecionados nesta pesquisa que se apoiam em Schein (1985) são Alavi, Kayworth e Leidner (2005), Donate e Guadamilas (2010), Zeng, Yang e McLean (2010), Rai (2011), Wiewora et al (2013) e Chang e Lin (2015). Eles entendem a CO como interações dinâmicas e contínuas entre as suposições básicas, valores e artefatos organizacionais de uma companhia compartilhados pelos membros de uma organização e que determinam como seus membros percebem, pensam e reagem ao ambiente. Nguyen e Mohamed (2011) agregam a esse conceito a abordagem de dois níveis de conceitos de CO com características visíveis e invisíveis.

Hofstede (1991) é a base de entendimento para CO de Souza, Ziviani e Goulart (2014). Para eles, CO pode ser vista como um universo cultural constituído de pressupostos, valores e crenças partilhados pelos indivíduos da organização, tendo derivação do ambiente social. Wang, Su e Yang (2011) entendem que CO é definida como um conjunto complexo de valores, crenças, suposições e símbolos (BARNEY, 1986) que guiam o comportamento dos membros da organização (HOFSTEDE, 2001).

De maneira diferente dos demais, Prado, Bem e Delfino (2013) baseiam-se em Mintzberg et al. (2000), e apresentam que CO são as crenças comuns que se refletem nas tradições e nos hábitos, bem como em manifestações mais tangíveis - histórias, símbolos, ou mesmo edifícios e produtos.

\subsection{Os modelos teóricos utilizados para investigar a temática}

O modelo teórico de GC mais utilizado nos artigos estudados é o modelo da espiral do conhecimento de Nonaka e Takeuchi (1995). É o caso de Donate e Guadamilas (2010), Rai (2011), Souza, Ziviani e Goulart (2014) e Zheng, Yang e McClean (2010).

A essência da abordagem proposta é o reconhecimento de que a criação do conhecimento não se refere apenas ao processamento de informações objetivas. Ela abrange a exploração dos insights tácitos e subjetivos das organizações e seus indivíduos, tornando-os disponíveis para testes e uso em toda a organização (NONAKA; TAKEUCHI, 1995).

Conforme Nonaka e Takeuchi (1995), a proposta é baseada na espiral do conhecimento, que consiste em um conjunto de quatro padrões de transformação do

Perspectivas em Gestão \& Conhecimento, João Pessoa, v. 7, Número Especial, p. 80-93, mar. 2017. 
conhecimento entre tácito e explícito e que coexistem dinamicamente nas organizações geradoras de conhecimento, conforme segue:

Tácito -> Tácito - quando um indivíduo compartilha diretamente seu conhecimento com outro num processo de socialização. A socialização é importante, mas não gera insights sistemático para a geração de conhecimento.

Tácito -> Explícito - quando os indivíduos conseguem articular os fundamentos de seus conhecimentos tácitos e transformá-los em padrões de conhecimento explícito para novos indivíduos. A externalização é uma das etapas vitais para a geração de criação de conhecimento.

Explícito -> Explícito - quando o conhecimento explícito de uma organização é combinado com outro conhecimento explícito para geração de novo conhecimento explícito. A combinação de conhecimento não significa necessariamente aumento da base de conhecimento da organização.

Explícito -> Tácito - quando o conhecimento explícito na organização é disseminado e internalizado pelos indivíduos gerando novo conhecimento tácito para o exercício de seus papéis. A internalização do novo conhecimento é uma etapa vital para a transmissão do novo conhecimento.

A gestão da criação do conhecimento ocorre na combinação sistemática destes quatro padrões de geração e transferência de conhecimento: socialização - externalização combinação - internalização (NONAKA; TAKEUCHI, 1995).

A espiral do conhecimento ou Modelo SECl - Socialization, Externalization, Combination, Internalization - foi complementada por Nonaka, Toyama e Konno (2000) por dois novos elementos que explicam como as empresas criam conhecimento: contexto de compartilhamento e ativos do conhecimento, que correspondem aos inputs, outputs e moderadores para o processo de criação do conhecimento (NONAKA; TOYAMA; KONNO, 2000).

No campo da CO, os modelos teóricos mais utilizados para a determinação dos fatores culturais que influenciam a GC e para a definição das variáveis que afetam as práticas de GC são os modelos dos valores conflitantes - Competing values framework - de Quinn e Rohrbaugh (1983) e Cameron and Quinn (2005), que empregam um Instrumento de Avaliação da Cultura Organizacional - Organisational Culture Assessment Instrument (OCAI), como nos trabalhos de Rai (2011a) e Wiewiora et al. (2013).

Outro modelo utilizado nos estudos da CO é modelo das dimensões culturais de Hofstede (LONNER; BERRY; HOFSTEDE, 1980), cujos aspectos principais são apresentados a seguir:

Individualismo-coletivismo - refere-se a modo como o indivíduo se manifesta em relação ao si próprio ou ao grupo social à que pertence.

Distância do Poder - refere-se à distância psicológica que as pessoas têm em relação as outras que ocupam postos ou classes superiores.

Masculinidade-feminilidade - refere-se a valores atribuídos a estereótipos de homens (remuneração, reconhecimento, promoção, desafio) e mulheres (inter-relacionamento, cooperação, área de convivência).

Aversão à incerteza - refere-se ao modo pelo qual as pessoas em uma dada cultura se comportam em relação à incerteza e a ambiguidade, ou seja, ao grau de intolerância ao imprevisto.

Confucionismo - refere-se a um conjunto de normas práticas para o cotidiano, inspiradas no Confucionismo chinês, tais como relações sociais, austeridade, vergonha, solidez e estabilidade pessoais, dignidade, etc.

O modelo evoluiu para perspectiva comportamental da cultura por meio do qual Hofstede et al. (1990) apresentaram dados empíricos a partir de subunidades de cultura

Perspectivas em Gestão \& Conhecimento, João Pessoa, v. 7, Número Especial, p. 80-93, mar. 2017. 
dentro das organizações, incluindo cultura orientada a resultados, rigidamente controlada, orientada ao trabalho, sistema fechado e orientada à profissão (HOFSTEDE et al., 1990).

\subsection{Os métodos de pesquisa utilizados para investigar a temática}

Com relação aos métodos de pesquisas empregados nos artigos estudos, pode-se observar uma ampliação do uso de métodos de pesquisa empírica quantitativos, conforme Quadro 3.

Quadro 3 - Métodos de Pesquisa e Coleta de Dados

\begin{tabular}{|l|l|l|}
\hline \multicolumn{1}{|c|}{ Referência } & \multicolumn{1}{c|}{ Método de pesquisa } & \multicolumn{1}{c|}{ Coleta de dados } \\
\hline $\begin{array}{l}\text { (ALAVI; KAYWORTH; LEIDNER, } \\
\text { 2005) }\end{array}$ & Estudo de caso único & $\begin{array}{l}\text { Entrevista e análise de } \\
\text { conteúdo }\end{array}$ \\
\hline $\begin{array}{l}\text { (AL-ALAWI; AL-ARZOOQI; } \\
\text { MOHAMMED, 2007) }\end{array}$ & $\begin{array}{l}\text { Pesquisa empírica quantitativa } \\
\text { e qualitativa }\end{array}$ & Survey e entrevistas \\
\hline $\begin{array}{l}\text { (ZHENG; YANG; MCLEAN, } \\
\text { 2010) }\end{array}$ & Pesquisa empírica quantitativa & Survey \\
\hline $\begin{array}{l}\text { (DONATE; GUADAMILLAS, } \\
\text { 2010) }\end{array}$ & Pesquisa empírica quantitativa & Survey \\
\hline (NGUYEN; MOHAMED, 2011) & Pesquisa empírica quantitativa & Survey \\
\hline (WANG; SU; YANG, 2011) & Pesquisa empírica quantitativa & Survey \\
\hline $\begin{array}{l}\text { (RAJNISH KUMAR RAI, 2011) } \\
\text { Estudo conceitual }\end{array}$ & $\begin{array}{l}\text { Pesquisa bibliográfica Análise } \\
\text { de conteúdo }\end{array}$ \\
\hline $\begin{array}{l}\text { (PRADO; BEM; DELFINO, 2013) } \\
\text { (WIEWIORA et al., 2013) }\end{array}$ & $\begin{array}{l}\text { Pétodo dialético } \\
\text { Pesquisa bibliográfica e fontes } \\
\text { secundárias }\end{array}$ \\
\hline $\begin{array}{l}\text { (SOUZA; ZIVIANI; GOULART, } \\
\text { 2014) }\end{array}$ & Pesquisa empírica quantitativa & $\begin{array}{l}\text { Survey, entrevistas e análise de } \\
\text { conteúdo }\end{array}$ \\
\hline (CHANG; LIN, 2015) & Pesquisa empírica quantitativa & Survey \\
\hline
\end{tabular}

Fonte: Autoria própria (2015)

Destaca-se o artigo base da presente pesquisa, de Alavi; Kayworthy e Leidner (2005), que utilizaram estudo de caso e coleta de dados por meio de entrevistas qualitativas sobre dos valores culturais que influenciam as práticas de GC. A partir desses autores muitos estudos empíricos quantitativos foram realizados para confirmar os estudos realizados inicialmente, com uso rigoroso de análises estatísticas, indicando maturidade no campo do conhecimento e busca por generalizações de resultados.

\subsection{Limitações de investigação relativas a método e teoria relatadas nas pesquisas}

Entre as principais limitações dos estudos explicitadas pelos autores analisados encontra-se o caráter de recorte temporal dos dados coletados, sendo recomendável estudos longitudinais para se analisar os efeitos dos fatores culturais nas práticas de GC ao longo do tempo em um ambiente dinâmicos de mudanças organizacionais e culturais.

Outra limitação apontada é o limitado número de casos ou participantes das pesquisas, o que aponta para a replicação dos estudos a um maior número de caso ou uma amostra mais representativa de empresas.

Perspectivas em Gestão \& Conhecimento, João Pessoa, v. 7, Número Especial, p. 80-93, mar. 2017. 
Alguns estudos apontaram ainda os aspectos culturais de seus países e a implicação para as CO das empresas participantes de suas amostras, sugerindo a replicação de tais estudos em contextos transnacionais.

Por fim, uma preocupação apontada foi a necessidade de se evitar uma única fonte de informação por empresa pesquisa diminuindo assim o risco de um viés do único respondente.

\subsection{Questões de pesquisa relevantes sobre o tema levantadas nos autores selecionados}

Entre as questões relevantes suscitadas pelas pesquisas realizadas e pela análise dos artigos desta revisão da literatura nos temas da Cultura Organizacional - $\mathrm{CO}$ e da Gestão do Conhecimento - GC, encontram-se as seguintes questões:

- $\quad$ Replicação de pesquisas empíricas em mais empresas;

- Incorporação de métodos qualitativos de observação e estudos longitudinais, para maior entendimento da relação entre CO e GC;

- Incorporação de outras variáveis além dos fatores culturais que podem influenciar as práticas de GC e seus resultados, tais como liderança, estrutura organizacional, sistemas de controle etc.;

- Novas conceptualizações teóricas para atualização dos modelos teóricos vigentes em função da dinâmica organizacional.

\section{DISCUSSÃO}

O grupo de artigos selecionados para a presente pesquisa mostram que a cultura organizacional e suas subculturas não só influenciam os comportamentos nas práticas de GC (tópico dos estudos anteriores), mas também afetam a seleção de tecnologias de GC e seu uso, as abordagens para o desenvolvimento da GC e os resultados esperados tanto no nível individual como organizacional (ALAVI; KAYWORTH; LEIDNER, 2005).

Fatores e valores culturais como comunicação estão relacionados positivamente com o compartilhamento de conhecimento (AL-ALAWI; AL-MARZOOQI; MOHAMMED, 2007). Tal pode ser decorrência do fato que a cultura determina as crenças básicas, valores e as normas relativas à criação, compartilhamento e utilização do conhecimento (ZHENG; YANG; MCLEAN, 2010). Essa constatação pede o apelo para a criação de uma cultura organizacional condizente com a GC (DAVENPORT; DE LONG; BEERS, 1998), como por exemplo, criando uma atmosfera amigável e não competitiva, baseada em participação, trabalho em equipe e informalidade. Tal fato promove uma propensão para o compartilhamento do conhecimento (WIEWIORA et al., 2013), elemento-chave para o sucesso das práticas de GC.

Algumas dimensões culturais, tais como, orientação a resultados, controle rígido e orientação ao trabalho, podem ter efeitos positivos ou negativos nos processos de criação, armazenamento, transferência e aplicação de conhecimento (CHANG; LIN, 2015). Deste modo a avaliação da cultura organizacional e do nível de desenvolvimento destas dimensões é um fator prévio importante para o sucesso das iniciativas de GC na organização em que se quer implantar.

Os resultados encontrados na presente pesquisa sugerem que o desenvolvimento de uma cultura organizacional que suporta a GC é fator chave para que as empresas possam se apropriar do valor de sua base de conhecimento (DONATE; GUADAMILLAS, 2010)

No âmbito da administração pública, a GC tem um conceito levemente diferenciado, uma vez que se refere ao conhecimento público, dos indivíduos que a compõem: a sociedade, os servidores e todas as esferas da administração pública. Esses componentes, se bem

Perspectivas em Gestão \& Conhecimento, João Pessoa, v. 7, Número Especial, p. 80-93, mar. 2017. 
articulados na GC, propiciarão melhor uso de seus recursos e funcionarão como alavanca impulsionadora ao sucesso da nação (PRADO; BEM; DELFINO, 2013).

\section{CONSIDERAÇÕES FINAIS}

Este artigo apresenta investigações nos temas da $\mathrm{CO}$ e da GC nos últimos cinco anos. O estudo baseou-se na revisão de artigos acadêmicos e estudos de pesquisas sobre o papel da CO na GC no Brasil e no mundo, por meio de levantamento no portal da CAPES.

Em síntese, os estudos sugerem que além da necessidade de se atentar para a importância que os valores de uma CO têm sobre as práticas de GC, é importante realizar a identificação da cultura ou subcultura prevalente em uma organização ou grupo. Disso decorre a necessidade da implementação de ações para a criação de um clima favorável, para a implementação de práticas de GC de sucesso nas organizações, contribuindo para a consecução dos objetivos organizacionais e aumento da satisfação dos colaboradores.

Este trabalho possui algumas limitações. Primeiro, uma base de dados única para identificação dos estudos, o que limita a avaliação. Igualmente, o número limitado de artigos e estudos, principalmente no Brasil, sinaliza oportunidades para uma avaliação mais completa de fatores e dimensões culturais ligados a GC.

Como sugestões de pesquisas futuras, há aspectos teóricos a serem aprofundados, que são formulados na forma de perguntas de pesquisa:

- $\quad$ Como dimensões culturais podem influenciar o comportamento de indivíduos e organizações em práticas de GC?

- Qual a evolução da influência cultural sobre o comportamento de indivíduos e organizações em uma determinada cultura?

- Que fatores organizacionais, individuais e coletivos contribuem positivamente ou negativamente combinados com a CO para o sucesso ou fracasso das práticas de GC?

- $\quad$ Como desenvolver a CO voltada para a GC no âmbito da Administração Pública Brasileira? Que lições podem ser tiradas de empresas privadas, da academia e de experiências bem-sucedidas em outros países?

\section{REFERÊNCIAS}

AL-ALAWI, A. I.; AL-MARZOOQI, N. Y.; MOHAMMED, Y. F. Organizational culture and knowledge sharing: critical success factors. Journal of Knowledge Management, v. 11, n. 2, p. 22-42, 10 abr. 2007.

ALAVI, M.; KAYWORTH, T. R.; LEIDNER, D. E. An Empirical Examination of the Influence of Organizational Culture on Knowledge Management Practices. Journal of Management Information Systems, v. 22, n. 3, p. 191-224, 1 dez. 2005.

ALAVI, M.; LEIDNER, D. E. Review: Knowledge management and knowledge management systems: Conceptual foundations and research issues. MIS quarterly, p. 107-136, 2001.

BARNEY, J. B. Organizational culture: can it be a source of sustained competitive advantage? Academy of management review, v. 11, n. 3, p. 656-665, 1986.

BATISTA, F. F. Modelo de gestão do conhecimento para a administração pública brasileira: como implementar a gestão do conhecimento para produzir resultados em benefício do cidadão. 2012.

CHANG, C. L.-H.; LIN, T.-C. The role of organizational culture in the knowledge management process. Journal of Knowledge Management, v. 19, n. 3, p. 433-455, 2015. 
CRESWELL, J. W. Research design: Qualitative, quantitative, and mixed methods approaches. [s.l.] Sage publications, 2013.

DAVENPORT, T. H.; DE LONG, D. W.; BEERS, M. C. Successful knowledge management projects. Sloan management review, v. 39, n. 2, p. 43-57, 1998.

DEMAREST, M. Understanding knowledge management. Long range planning, v. 30, n. 3, p. 321-384, 1997.

DONATE, M. J.; GUADAMILLAS, F. The effect of organizational culture on knowledge management practices and innovation. Knowledge and Process Management, v. 17, n. 2, p. 82-94, 1 abr. 2010.

GONDIM, S. M. G.; BORGES-ANDRADE, J. E.; BASTOS, A. V. B. Psicologia do Trabalho e das Organizações: Produção científica e desafios metodológicos. Psicologia em pesquisa, v. 4, n. 2, p. 84-99, 2010.

HEISIG, P. Harmonisation of knowledge management - comparing $160 \mathrm{KM}$ frameworks around the globe. Journal of knowledge management, v. 13, n. 4, p. 4-31, 2009.

HOFSTEDE, G. et al. Measuring organizational cultures: A qualitative and quantitative study across twenty cases. Administrative science quarterly, p. 286-316, 1990.

JESSON, J.; MATHESON, L.; LACEY, F. M. Doing your literature review: traditional and systematic techniques. [s.I.] Sage, 2011.

LONNER, W. J.; BERRY, J. W.; HOFSTEDE, G. H. Culture's Consequences: International Differences in Work-Related Values. University of Illinois at Urbana-Champaign's Academy for Entrepreneurial Leadership Historical Research Reference in Entrepreneurship, 1980.

NGUYEN, H. N.; MOHAMED, S. Leadership behaviors, organizational culture and knowledge management practices; An empirical investigation. Journal of Management Development, $\mathrm{v}$. 30, n. 2, p. 206-221, 2011.

NONAKA, I.; TAKEUCHI, H. The knowledge-creating company: How Japanese companies create the dynamics of innovation. [s.l.] Oxford university press, 1995.

NONAKA, I.; TOYAMA, R.; KONNO, N. SECl, Ba and leadership: a unified model of dynamic knowledge creation. Long range planning, v. 33, n. 1, p. 5-34, 2000.

PRADO, M. L.; BEM, R. M.; DELFINO, N. Desafios à implantação da gestão do conhecimento: a questão cultural nas organizações públicas federais brasileiras / Challenges to implement knowledge management: the cultural issue in the brazilian federal government organization. Revista Digital de Biblioteconomia e Ciência da Informação, v. 11, n. 2, p. 123, 2013.

QUINN, R. E.; ROHRBAUGH, J. A spatial model of effectiveness criteria: Towards a competing values approach to organizational analysis. Management science, v. 29, n. 3, p. 363-377, 1983.

RAI, R. K. Knowledge management and organizational culture: a theoretical integrative framework. Journal of Knowledge Management, v. 15, n. 5, p. 779-801, 2011.

ROWLEY, J. Knowledge management in pursuit of learning: the learning with knowledge cycle. Journal of Information Science, v. 27, n. 4, p. 227-237, 2001.

SCHEIN, E. H. Cultura organizacional e liderança. [s.I.] Atlas, 2009.

SOLIMAN, F.; SPOONER, K. Strategies for implementing knowledge management: role of human resources management. Journal of knowledge management, v. 4, n. 4, p. 337-345, 2000.

Perspectivas em Gestão \& Conhecimento, João Pessoa, v. 7, Número Especial, p. 80-93, mar. 2017. 
SOUZA, F. H.; ZIVIANI, F.; GOULART, F. M. F. Interseção entre a Gestão do Conhecimento e a Cultura Organizacional: Um Estudo sobre a Percepção dos Gerentes de Projetos. Revista de Gestão e Projetos, v. 5, n. 2, p. 51, 2014.

SVEIBY, K.-E.; SIMONS, R. Collaborative climate and effectiveness of knowledge work-an empirical study. Journal of Knowledge Management, v. 6, n. 5, p. 420-433, 2002.

TAKEUCHI, H.; NONAKA, I. Gestão do conhecimento. [s.I.] Bookman, 2008.

WANG, D.; SU, Z.; YANG, D. Organizational culture and knowledge creation capability. Journal of Knowledge Management, v. 15, n. 3, p. 363-373, 2011.

WIEWIORA, A. et al. Organizational culture and willingness to share knowledge: A competing values perspective in Australian context. International Journal of Project Management, v. 31, n. 8, p. 1163-1174, 2013.

ZHENG, W.; YANG, B.; MCLEAN, G. N. Linking organizational culture, structure, strategy, and organizational effectiveness: Mediating role of knowledge management. Journal of Business Research, v. 63, n. 7, p. 763-771, jul. 2010. 